\title{
Comparison of the Using Ability Between a Smartphone and a Conventional Mobile Phone in People With Cervical Cord Injury
}

\author{
Seongkyu Kim, MD, Bum-Sulk Lee, MD, Ji Min Kim
}

Department of Rehabilitation Medicine, National Rehabilitation Center, Seoul, Korea

Objective To investigate the ability of spinal cord injury (SCI) patients in the use mobile cellular devices, especially the smartphone.

Methods Seventeen people with motor complete cervical SCI participated in the study. The assist-devices deemed most fitting were introduced to the patients: a mouth stick, multifunctional splint, activities of daily living (ADL) splint, universal cuff or none of the above. To determine the effective devices, a Multi-Directional Click Test (MDCT), Phone Number Test (PNT), and individual satisfaction inquiry were used. The most appropriate assist device was selected by MDCT. Subsequently PNT and individual satisfaction inquiry were performed with the conventional model and compared.

Results Those with C4 cord injury chose mouth stick. Those with C5 cord injury chose multifunctional splint ( 3 people) and ADL splint ( 2 people). Those with C6 cord injury chose universal cuff ( 3 people) or bare hands only. Those with C7 cord injury chose universal cuff ( 3 people). With a smartphone, all participants were able to complete the PNT. With a conventional model, only twelve participants $(71 \%)$ were able to complete the same test. While it took $26.8 \pm 6.8$ seconds with a conventional model to complete PNT, the same test took $18.8 \pm 10.9$ seconds to complete with a smartphone $(\mathrm{p}<0.05)$. Overall, participants expressed higher satisfaction when using a smartphone.

Conclusion The results offer a practical insight into the appropriate assist devices for SCI patients who wish to use mobile cellular devices, particularly smartphones. When the SCI patients are given the use of a smartphone with the appropriate assist devices, the SCI patients are expected to access mobile cellular device faster and with more satisfaction.

Keywords Cervical cord injury syndrome, Assistive device, Smartphone

() This is an open-access article distributed under the terms of the Creative Commons Attribution Non-Commercial License (http://creativecommons.org/ licenses/by-nc/3.0) which permits unrestricted noncommercial use, distribution, and reproduction in any medium, provided the original work is properly cited. Copyright $\odot 2014$ by Korean Academy of Rehabilitation Medicine 


\section{INTRODUCTION}

Presently a computer and telephone are essential devices for most people. They play important roles in communication, access of information and education [1]. From a few years ago, mobile devices, especially the smartphone, have emerged as one of the most important devices in communication.

Penetration of smartphones has rapidly increased up to $61.5 \%$ in 2012 , compared with penetration of $39.6 \%$ in 2011 in the Republic of Korea. However a smaller ratio of people with disability has the use of smartphones in Korea, at $23.1 \%$ [2].

There have been studies on the use of computers in people with disability. The studies showed that a disabled person used a computer more easily when provided the appropriate assistive devices $[3,4]$. There is no study on the smartphone usage abilities in people with disability.

The purpose of this study was to investigate the ability of spinal cord injury (SCI) patients to use a mobile cellular device, especially a smartphone. This investigation was intended to determine the appropriate assistive devices for SCI patients, taking into account the neurological disability level, chiefly by comparing the motor functions necessary for the use of a smartphone and a conventional model.

\section{MATERIALS AND METHODS}

Seventeen people with motor complete cervical SCI participated in the study. The candidate assistive devices deemed most fitting were introduced to patients: a mouth stick, multifunctional splint, activities of daily living (ADL) splint, universal cuff or bare hands only (Fig. 1). Two types of mobile phones were used in this study. For a smartphone, iPhone4 (Apple Inc., Cupertino, CA, USA) with capacitive touch screen was selected. For the conventional mobile phone model, IM-S480S (Pantech, Seoul, Korea) was selected. This device has the classical resistive key pad interface.

To determine the efficiency of the candidate devices, the Multi-Directional Click Test (MDCT), Phone Number Test (PNT), and individual satisfaction inquiry were used. MDCT was based on ISO 9241 (part 9) specified the ergonomics requirements for non-keyboard input devices which may be used in conjunction with a visual display terminal. It recommends performance tests for input devices and has the objective of evaluating the efficiency of the device during commonly performed tasks. According to ISO 9241 (part 9), click and moving the pointer were

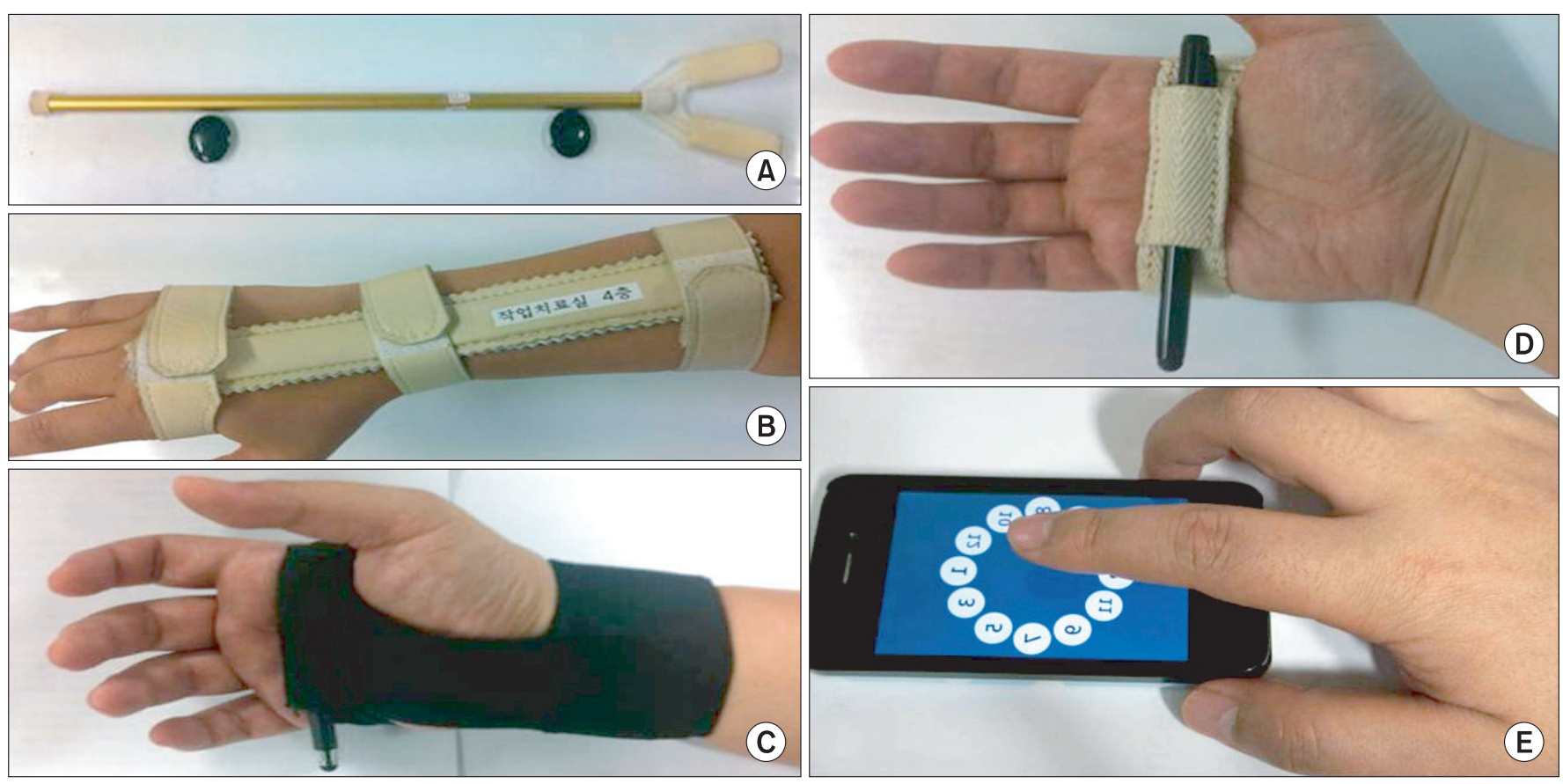

Fig. 1. Assistive devices. (A) Mouth stick, (B) activities of daily living wrist splint with stylus, (C) multifuctional splint with stylus, (D) universal cuff with stylus, and (E) bare hands only. 
the most important components in non-keyboard input devices. A previous study showed that multi-directional pointing better reflected the performance of devices over one-directional pointing $[4,5]$.

MDCT measures the time that it takes for a patient to click the numbers, from 1 to 12, arranged in a circle (Fig. 2 ). When the numbers are clicked in sequence, the candidates are asked to move the hand in various directions. The test was performed three times, and the average time was measured.

PNT measures the time a patient takes to input an 11-digit number, a length similar to a typical phone number. Ten series of numbers similar to a telephone number were prepared, and each candidate input a randomly selected telephone number. The test was performed three times, and average times were measured.

Individual satisfaction was evaluated in a five-point scale (1, unsatisfactory; 5 , satisfactory), of which the grading criteria consisted of speed, accuracy, endurance, convenience and overall satisfaction.

By considering the residual motor function, the participants applied assistive devices. People with SCI on C4 could not apply other assistive devices without a mouth stick, and they performed the test with a mouth stick only. People with SCI on C5 performed the test with ADL splint with stylus and multifunctional splint with stylus, which supported their wrist and locked the stylus on the hand. People with SCI on C6 and C7, who could control their wrist extensor, tried universal cuff with stylus and bare hands without any assistive devices. When a participant could not move the stylus on a smartphone or aban-

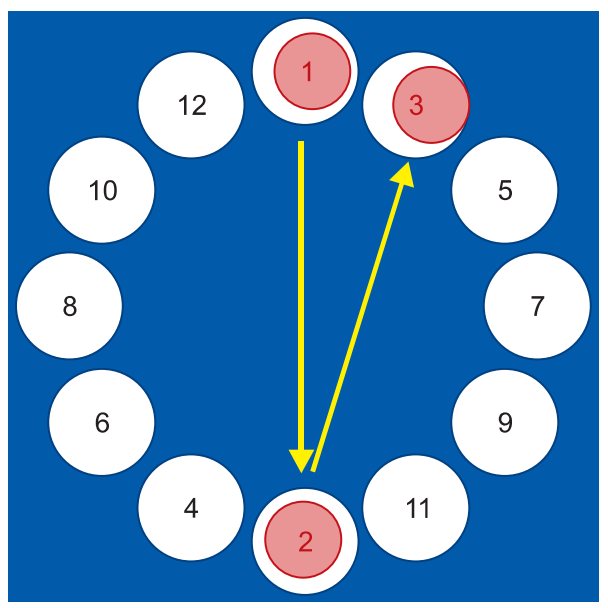

Fig. 2. Representation of the sequence of object selection. doned the test, the trial was categorized as 'not testable.' The most appropriate assistive device was selected by the results of MDCT.

Subsequently PNT and individual satisfaction inquiry were performed using the assistive device that passed MDCT with the highest scores. PNT and individual satisfaction inquiry were repeated with a conventional mobile phone, with the appropriate assistive device selected by MDCT.

\section{RESULTS}

There was a total of 17 participants, 11 males and 6 females (Table 1). Three participants had SCI on C4 level, five on C5 level, six on C6 level and three on C7 level. Those with $\mathrm{C} 4$ cord injury chose mouth stick. Those with C5 cord injury chose multifunctional splint with stylus (3 people) and ADL splint with stylus (2 people). Those with C6 cord injury chose universal cuff with stylus (3 people) or bare hands. Those with $\mathrm{C} 7$ cord injury chose universal cuff with stylus (3 people) (Table 2).

With the smartphone, all people were able to complete the PNT. With the conventional mobile phone, only 12 participants $(71 \%)$ were able to complete the same test. It should be noted that of 5 participants who could not

Table 1. Demographic data

\begin{tabular}{ccccc}
\hline Subject & $\begin{array}{c}\text { Level of } \\
\text { injury }\end{array}$ & Gender & Age & $\begin{array}{c}\text { Duration } \\
\text { (mo) }\end{array}$ \\
\hline 1 & C4 & M & 41 & 11 \\
\hline 2 & C4 & M & 63 & 20 \\
\hline 3 & C4 & M & 55 & 24 \\
\hline 4 & C5 & M & 47 & 15 \\
\hline 5 & C5 & M & 41 & 19 \\
\hline 6 & C5 & M & 35 & 8 \\
\hline 7 & C5 & M & 44 & 3 \\
\hline 8 & C5 & M & 51 & 6 \\
\hline 9 & C6 & M & 37 & 12 \\
\hline 10 & C6 & M & 33 & 8 \\
\hline 11 & C6 & M & 41 & 36 \\
\hline 12 & C6 & F & 52 & 4 \\
\hline 13 & C6 & F & 63 & 6 \\
\hline 14 & C6 & F & 28 & 11 \\
\hline 15 & C7 & F & 31 & 5 \\
\hline 16 & C7 & F & 35 & 7 \\
\hline 17 & C7 & F & 42 & 6 \\
\hline
\end{tabular}


Table 2. Results of MDCT and selection of assist-devices (unit, sec)

\begin{tabular}{ccccccc}
\hline Subject & $\begin{array}{c}\text { Level of } \\
\text { injury }\end{array}$ & $\begin{array}{c}\text { Mouth stick } \\
\text { (sec) }\end{array}$ & $\begin{array}{c}\text { ADL splint with } \\
\text { stylus (sec) }\end{array}$ & $\begin{array}{c}\text { MFS with } \\
\text { stylus (sec) }\end{array}$ & $\begin{array}{c}\text { U-cuff with } \\
\text { stylus (sec) }\end{array}$ & $\begin{array}{c}\text { Hand } \\
\text { (sec) }\end{array}$ \\
\hline 1 & C4 & 13.75 & NT & NT & NT & NT \\
2 & C4 & 15.70 & NT & NT & NT & NT \\
\hline 3 & C4 & 16.75 & NT & NT & NT & NT \\
4 & C5 & - & 23.05 & 22.12 & NT & NT \\
\hline 5 & C5 & - & 26.11 & 20.16 & NT & NT \\
6 & C5 & - & 25.55 & 23.50 & NT & NT \\
\hline 7 & C5 & - & 28.01 & 30.58 & NT & NT \\
\hline 8 & C5 & - & 26.00 & 29.20 & NT & NT \\
\hline 9 & C6 & - & - & - & 16.51 & 15.21 \\
10 & C6 & - & - & - & 16.20 & 15.39 \\
\hline 11 & C6 & - & - & - & 18.12 & 16.32 \\
\hline 12 & C6 & - & - & - & 18.61 & NT \\
\hline 13 & C6 & - & - & - & 11.24 & NT \\
14 & C6 & - & - & - & 11.96 & 26.20 \\
\hline 15 & C7 & - & - & - & 10.16 & 10.22 \\
\hline 16 & C7 & - & - & - & 11.20 & 12.29 \\
\hline 17 & C7 & - & - & 10.20 & 11.87 \\
\hline
\end{tabular}

MDCT, Multi-Directional Click Test; ADL, activities of daily living; MFS, multifunctional splint; U-cuff, universal cuff; NT, not testable.

(A)

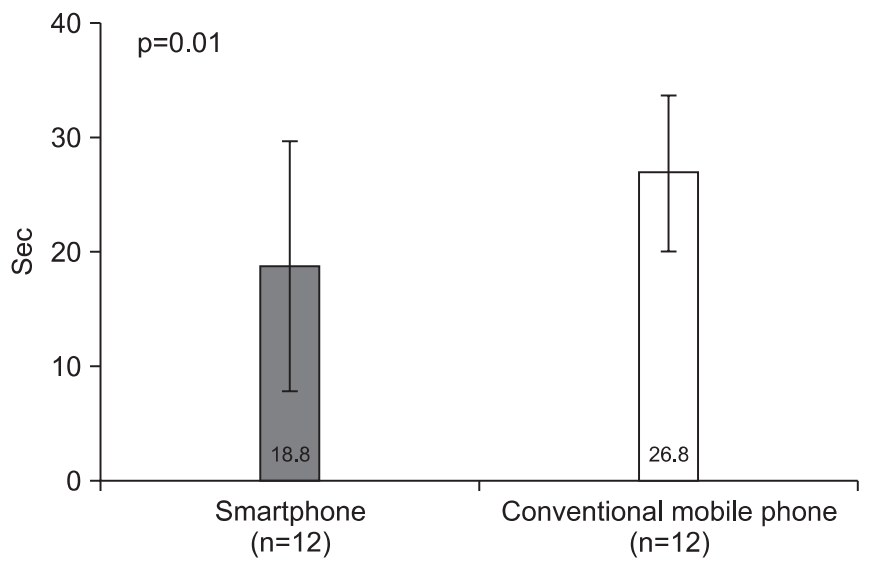

(B)

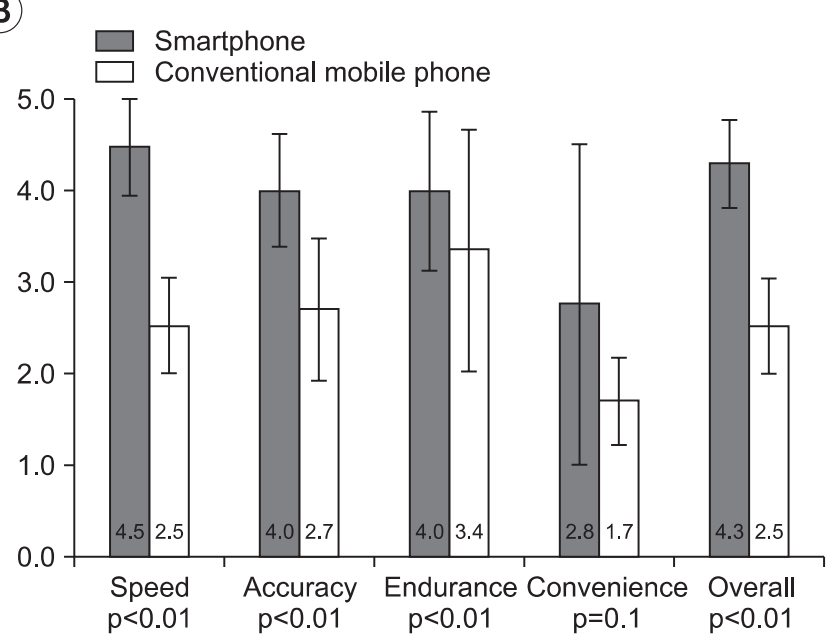

Fig. 3. Results of (A) comparison of typing speed in the Phone Number Test and (B) comparison of subjective satisfaction (5-point scale) between a smartphone and a conventional mobile phone.

complete the test, 3 had C5 cord injury, 1 had C6 cord injury, and 1 had C7 cord injury. Their inability to perform the task was mainly due to the shortcomings of the muscle strength. While it took $26.8 \pm 6.8$ seconds with a conventional mobile phone to complete PNT, the same test took $18.8 \pm 10.9$ seconds to complete with a smartphone $(\mathrm{p}<0.05)$ (Fig. 3A). Overall, participants expressed more satisfaction when using a smartphone in the individual satisfaction inquiry $(\mathrm{p}<0.05)$ (Fig. 3B). 
Table 3. Results of MDCT and PNT

\begin{tabular}{|cccc}
\hline Subject & $\begin{array}{c}\text { Level of } \\
\text { injury }\end{array}$ & $\begin{array}{c}\text { PNT on smart- } \\
\text { phone (sec) }\end{array}$ & $\begin{array}{c}\text { PNT on } \\
\text { conventional } \\
\text { mobile phone } \\
\text { (sec) }\end{array}$ \\
\hline 1 & $\mathrm{C} 4$ & 44.45 & 25.53 \\
\hline 2 & $\mathrm{C} 4$ & 10.89 & 24.12 \\
\hline 3 & $\mathrm{C} 4$ & 11.02 & 20.12 \\
\hline 4 & $\mathrm{C} 5$ & 28.08 & $\mathrm{NT}$ \\
\hline 5 & $\mathrm{C} 5$ & 19.02 & $\mathrm{NT}$ \\
\hline 6 & $\mathrm{C} 5$ & 22.71 & $\mathrm{NT}$ \\
\hline 7 & $\mathrm{C} 5$ & 26.00 & 41.00 \\
\hline 8 & $\mathrm{C} 5$ & 25.00 & 38.00 \\
\hline 9 & $\mathrm{C} 6$ & 9.96 & $\mathrm{NT}$ \\
\hline 10 & $\mathrm{C} 6$ & 9.00 & 22.30 \\
\hline 11 & $\mathrm{C} 6$ & 8.54 & 21.80 \\
\hline 12 & $\mathrm{C} 6$ & 26.16 & 27.89 \\
\hline 13 & $\mathrm{C} 6$ & 23.13 & 28.92 \\
\hline 14 & $\mathrm{C} 6$ & 21.04 & 30.20 \\
\hline 15 & $\mathrm{C} 7$ & 9.85 & $\mathrm{NT}$ \\
\hline 16 & $\mathrm{C} 7$ & 10.33 & 22.12 \\
\hline 17 & $\mathrm{C} 7$ & 9.86 & 19.80 \\
\hline
\end{tabular}

MDCT, Multi-Directional Click Test; PNT, Phone Number Test; NT, not testable.

\section{DISCUSSION}

While all of participants who had SCI on C7 level preferred universal cuff with stylus, 3 participants with SCI on $\mathrm{C} 7$ level selected universal cuff with stylus, and the rest preferred bare hands. People with SCI on C7 level had more functional arms and hands than people with SCI on C6 level, and it was expected that assistive devices were required more for people with SCI on C6 level. For using universal cuff with stylus, it is essential to keep the forearm neutral. People with SCI on C6 level have weak pronator and supinator muscles, and they appealed difficulties in controlling the forearms. In addition, the appropriate assistive device was determined on the results of MDCT, not on subjective preference and satisfaction. Hence ease of wear or fatigue was not considered.

There are some limitations in this study. First, the sample size was small. In this study, two to three participants were included in each neurological level of injury. With more participants, the most appropriate assistive device for each neurological level of injury may be proved statistically.

In this study, only the mouth stick was applied in SCI on $\mathrm{C} 4$ level. There are studies on the appropriate computer interface device for patients with high cervical cord injury $[6,7]$. In the study by Kim et al. [6], patients with SCI on C4 level were enabled to click, drag and type with Head Z mouse (RS Care Systems, Daegu, Korea), SmartNav 4AT (NaturalPoint, Corvallis, OR, USA), and IntegraMouse (LifeTool Solutions GmbH, Linz, Austria). However there are no previous studies on the appropriate device for smartphones. In the future, the development of new assistive and interface devices for people with SCI on $\mathrm{C} 4$ level is expected.

The result of the study offers a practical insight into the appropriate assistive devices for SCI patients who wish to use mobile cellular devices, particularly smartphones. When the SCI patients are given the use of a smartphone with appropriate assistive devices, it is expected for SCI patients to access mobile cellular devices faster and with more satisfaction.

\section{CONFLICT OF INTEREST}

No potential conflict of interest relevant to this article was reported.

\section{REFERENCES}

1. Blain S, McKeever P, Chau T. Bedside computer access for an individual with severe and multiple disabilities: a case study. Disabil Rehabil Assist Technol 2010;5:35969.

2. Choi DJ, Jung BM, Lee JW. Evaluation for information gap index on 2012. 1st ed. Seoul: National Information Society Agency; 2013.

3. Eom GM, Lee JM, Kim CS, Kong SJ, Lee BS, Lee KH. Manipulation performance and satisfaction of the computer mouse interface in the cervical spinal cord injury patients. J Korean Acad Rehabil Med 2006;30:230-5.

4. Chen HC, Chen CL, Lu CC, Wu CY. Pointing device usage guidelines for people with quadriplegia: a simulation and validation study utilizing an integrated pointing device apparatus. IEEE Trans Neural Syst Rehabil Eng 2009;17:279-86. 
5. Douglas SA, Kirkpatrick AE, Scott MacKenzie IS. Testing pointing device performance and user assessment with the ISO 9241, Part 9 standard. Proceedings of the SIGCHI conference on Human Factors in Computing Systems; 1999 May 15-20; Pittsburgh, PA. p. 215-22.

6. Kim DG, Lee BS, Lim SE, Kim DA, Hwang SI, Yim YL, et al. The selection of the appropriate computer interface device for patients with high cervical cord injury. Ann Rehabil Med 2013;37:443-8.

7. Pereira CA, Bolliger Neto R, Reynaldo AC, Luzo MC, Oliveira RP. Development and evaluation of a headcontrolled human-computer interface with mouselike functions for physically disabled users. Clinics (Sao Paulo) 2009;64:975-81. 